\title{
POWER SYSTEM SECURITY ENHANCEMENT BY OPTIMAL PLACEMENT OF UPFC
}

\author{
Jai Govind Singh \\ Energy, SERD \\ Asian Institute of Technology, \\ Klong Luang, Pathumthani- \\ 12120, Thailand \\ jgsingh@ait.ac.th
}

\author{
Sri Niwas Singh, Suresh Chandra Srivastava \\ Department of Electrical Engineering, \\ Indian Institute of Technology Kanpur \\ Uttar Pradesh, India \\ $\underline{\text { snsingh@iitk.ac.in and scs@iitk.ac.in }}$
}

\author{
Lennart Söder \\ Electrical Power System, \\ The Royal Institute of Technology, \\ Stockholm, Sweden \\ lennart.soder@ee.kth.se
}

\begin{abstract}
In this paper, a new approach to enhance power system security has been suggested by optimal placement of UPFC based on sensitivity indices. The sensitivity indices have been obtained, using ac power flow method, in terms of change in line real power flow Performance Index (PI) with respect to the change in the UPFC parameters viz., injected voltage magnitude and phase angle. In order to validate the accuracy of the proposed method, an Optimal Power Flow (OPF) formulation has been used to measure the security in terms of minimum PI values, with placement of UPFC based on the proposed sensitivity factors. The results have also been compared with existing dc power flow based method on IEEE 30-bus and practical NREB 246-bus Indian systems. Test results obtained on the two systems show that the new sensitivity factors could be effectively used for the optimal placement of UPFC in order to enhance the static security of the power system.
\end{abstract}

\section{KEY WORDS}

Unified power flow controller, Optimal placement, OPF, PI sensitivity, System security.

\section{Introduction}

In emerging electric power systems, increased transactions may often lead to the situations where the systems no longer remain in the secure operating region. The security $[18,19]$ of a power system can be defined as its ability to withstand a set of severe, but credible, contingencies and being in an acceptable new steady state condition. Various factors, such as environmental, right-of-way and high installation cost, limit the expansion of the transmission networks. Utilities try to maximize the utilization of the existing transmission asset that may, sometimes, lead to insecure operation of the system. Increased loading in power systems, combined with deregulation of the power industry, motivates the use of Flexible AC Transmission Systems (FACTS) controllers [13], such as Thyristor Controlled Series Compensator (TCSC), Thyristor Controlled Phase Angle Regulator (TCPAR) and Unified Power Flow Controller (UPFC), for power flow control as a cost-effective means of dispatching specified power transactions and maintaining system's security. However, due to the high cost of these controllers, it is necessary to locate them optimally in the network.
The line real power flow Performance Index (PI) is a good measure to the power system security for especially to avoid the equipment outage related contingency. By continuously monitoring the Performance Index (PI), the level and appropriate control actions could be predicted to maintain the system remains operable subjected to post disturbances or outages. There are few work reported in literatures which suggested different methodology for enhancement of power system security by FACTS controllers. However, most of method used many assumptions like dc power flow to find out the location of FACTS controllers and security measures, which are less accurately represented.

Reference [5], deals with the optimal location of TCSC and [7] has presented a method of optimal location of UPFC in view of enhancing the security. These work used dc power flow approximation model and, hence, less accurate and also did not suggest a method to determine the optimal settings of these controllers. Momoh et al. [6] suggested the use of phase shifter for security enhancement and obtained its parameters using Optimal Power Flow (OPF) formulation. Yorino et al. [9] proposed a new formulation for reactive power planning problem including the allocation of FACTS devices, but the results have been demonstrated on very small system. In [10], two objective functions have been considered, viz. maximization of system security and minimization of investment cost of FACTS devices, for their optimal placement. The effectiveness of the method was tested only on IEEE 14-bus system. Three heuristic methods, viz. Genetic Algorithm, Tabu Search and Simulated Annealing, have been applied in [11] for optimal location of the FACTS devices.

In this paper, indices, based on ac power flow, representing sensitivity of a line real power flow Performance Index (PI) with respect to UPFC series control parameters has been proposed for its optimal location in view of enhancing the system security under different operating conditions. The proposed sensitivity factors have been derived considering the impact of change in the system loading on bus voltages and angles. The effectiveness of the proposed method has been demonstrated on IEEE 30-bus and practical 246-bus Indian system utilizing an optimal power flow model that minimizes the line flow PI value. The results have been compared with an existing approach utilizing dc power flow approximation [15]. 


\section{Static Model of UPFC}

The Unified Power Flow Controller (UPFC) [1,2,7,12] can be viewed as a combination of Static Synchronous Compensator (STATCOM) and a Static Synchronous Series Compensator (SSSC). Both the compensators are coupled via a common dc-link, which allows bi-directional flow of real power between the series output terminals of the SSSC and the shunt output terminals of the STATCOM. The conventional UPFC consisting of two converters is capable of simultaneously controlling three power system quantities, i.e. the bus voltage at substation, real and reactive power flows in a line. UPFC has three controllable parameters, namely the magnitude and the angle of inserted voltage $\left(V_{s}\right.$, $\phi_{s}$ ) and the magnitude of the shunt current $\left(I_{q}\right)$. The real component $\left(I_{T}\right)$ of the shunt current is in phase and current component $\left(I_{q}\right)$ is in quadrature with the voltage at bus- $i$. In this work, $I_{q}$ was taken as zero because having less effect on real power flow control. The equivalent circuit of the UPFC placed in line- $k$, connected between bus- $i$ and bus- $j$ having series impedance $r_{i j}+j x_{i j}\left(=1 /\left(g_{i j}+j b_{i j}\right)\right)$, is shown in Fig. 1 and a power injection model of UPFC is shown in Fig. 2.

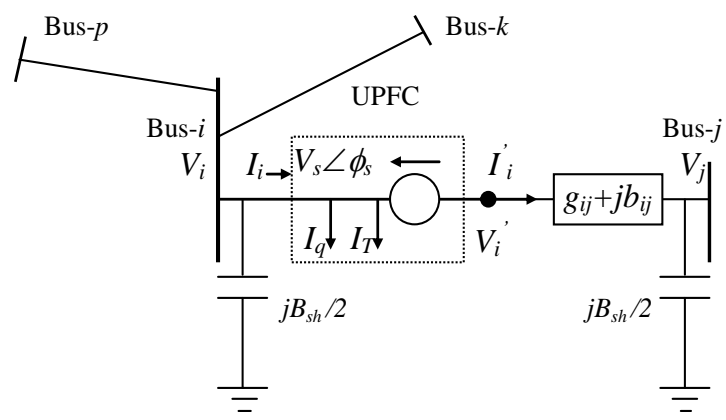

Figure 1. Equivalent circuit of UPFC

The injected active $\left(P_{i u}\right)$ and reactive $\left(Q_{i u}\right)$ powers, by UPFC only, at bus- $i$ will be given as

$$
\begin{aligned}
P_{i u}=- & -V_{s}^{2} g_{i j}-2 V_{s} V_{i} g_{i j} \cos \left(\phi_{s}-\delta_{i}\right)+ \\
& V_{s} V_{j}\left[g_{i j} \cos \left(\phi_{s}-\delta_{j}\right)+b_{i j} \sin \left(\phi_{s}-\delta_{j}\right)\right] \\
Q_{i u}= & V_{i} I_{q}+V_{i} V_{s}\left[g_{i j} \sin \left(\phi_{s}-\delta_{i}\right)+b_{i j} \cos \left(\phi_{s}-\delta_{i}\right)\right]
\end{aligned}
$$

Similarly, the real $\left(P_{j u}\right)$ and reactive $\left(Q_{j u}\right)$ power injections, by UPFC only, at bus- $j$ can be derived as

$$
\begin{aligned}
& P_{j u}=V_{j} V_{s}\left(g_{i j} \cos \left(\phi_{s}-\delta_{j}\right)-b_{i j} \sin \left(\phi_{s}-\delta_{j}\right)\right) \\
& Q_{j u}=-V_{j} V_{s}\left(g_{i j} \sin \left(\phi_{s}-\delta_{j}\right)+b_{i j} \cos \left(\phi_{s}-\delta_{j}\right)\right)
\end{aligned}
$$

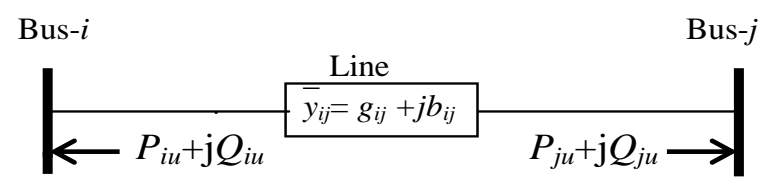

Figure 2. Power injection model of UPFC

\section{Methodology Development for Optimal Placement of UPFC}

The relative severity of the system loading under normal and contingency cases, using line real power flow Performance Index (PI) [14], can be written as

$$
P I=\sum_{m=1}^{N_{l}} \frac{w_{m}}{2 a}\left(\frac{P_{m}}{P_{m}^{\max }}\right)^{2 a}
$$

where, $P_{m}$ is the real power flow and $P_{m}{ }^{m a x}$ is the rated capacity of line- $m, a$ is an exponent and $w_{m}$ is a real nonnegative weighting coefficient, which may be used to reflect the relative importance of the lines. In this work, $w_{m}$ has been taken as 1.0 for all the lines. $N_{l}$ is the total line number in power network system.

\subsection{PI Sensitivity using de Power Flow Approximation}

The control parameters of the UPFC, considered in this work, are the magnitude and angle of the series injected voltage, $V_{s}$ and $\phi_{s}$, respectively. The PI sensitivity factors with respect to the control parameters of the UPFC can be defined as

$$
\begin{aligned}
& C_{I}^{k}=\left.\frac{\partial P I}{\partial V_{s}}\right|_{V_{s}=0}=\text { PI Sensitivity with respect to } V_{s} \\
& C_{2}^{k}=\left.\frac{\partial P I}{V_{s} \partial \phi_{s}}\right|_{\phi_{s}=0}=\text { PI Sensitivity with respect to } \phi
\end{aligned}
$$

For deriving the PI sensitivity terms using dc power flow approximation, the value of ' $a$ ' in equation (5) has been taken as 2 . Using equations (6) and (7), the sensitivity of PI with respect to the UPFC series parameters, in $k^{\text {th }}$ line, $X_{k}\left(V_{s}\right.$ and $\left.\phi_{s}\right)$, can be written as

$$
\frac{\partial \boldsymbol{P I}}{\partial X_{k}}=\sum_{m=1}^{N_{l}} w_{m} \boldsymbol{P}_{m}^{3}\left(\frac{1}{\boldsymbol{P}_{m}^{\max }}\right)^{4} \frac{\partial \boldsymbol{P}_{m}}{\partial X_{k}}
$$

The real power flow $\left(P_{m}\right)$, in a line- $m$, can be represented in terms of bus real power injections using $\mathrm{dc}$ power flow equations, as

$$
P_{m}= \begin{cases}\sum_{\substack{n=1 \\ n \neq s}}^{N_{b}} S_{m n} P_{n} & \text { for } m \neq k \\ \sum_{\substack{n=1 \\ n \neq s}}^{N_{b}} S_{m n} P_{n}+P_{j u} & \text { for } m=k\end{cases}
$$

where, $S_{m n}$ is the $m n^{\text {th }}$ element of sensitivity matrix $[S]$, which relates line flow with power injections at the buses without placement of UPFC [7], $N_{b}$ is the number of buses in the system and $s$ is the slack bus. Assume that the line- $k$, between bus- $i$ and bus- $j$, is the line containing the UPFC. The effect of UPFC can be represented as additional power injections at bus- $i$ and bus- $j$, as shown in Fig. 2 .

Using equations (8) and (9), the following relationship can be derived, 


$$
\begin{aligned}
\frac{\partial P_{m}}{\partial X_{k}}= \begin{cases}\left(S_{m i} \frac{\partial P_{i u}}{\partial X_{k}}+S_{m j} \frac{\partial P_{j u}}{\partial X_{k}}\right) & \text { for } m \neq k \\
\left(S_{m i} \frac{\partial P_{i u}}{\partial X_{k}}+S_{m j} \frac{\partial P_{j u}}{\partial X_{k}}\right)+\frac{\partial P_{j u}}{\partial X_{k}} & \text { for } m=k\end{cases} \\
\text { The terms }\left.\frac{\partial P_{i u}}{\partial X_{k}}\right|_{X_{k}=0} \text { and }\left.\frac{\partial P_{j u}}{\partial X_{k}}\right|_{X_{k}=0} \text { can be obtained }
\end{aligned}
$$

by partially differentiating the equations (1) and (3), with respect to the UPFC's series parameters.

\subsection{Proposed PI Sensitivity Factors using ac Power Flow Approximation}

The real power mismatch $\left(P_{i s}\right)$ and reactive power mismatch $\left(Q_{i s}\right)$ at any bus- $i$ can be expressed in terms of voltage magnitudes $(V)$, voltage angles $(\delta)$ and elements of bus admittance matrix $(Y)$ as

$$
\begin{aligned}
& P_{i s}=P_{G i}+P_{i u}-P_{D i}-\operatorname{Re}\left(V_{i} \sum_{j=1}^{\mathrm{N}_{\mathrm{b}}}\left(V_{j} Y_{i, j}\right)^{*}\right) \\
& Q_{i s}=Q_{G i}+Q_{i u}-Q_{D i}-\operatorname{Im}\left(V_{i} \sum_{j=1}^{\mathrm{N}_{\mathrm{b}}}\left(V_{j} Y_{i, j}\right)^{*}\right)
\end{aligned}
$$

where, $P_{G i}, Q_{G i}$ are the real and reactive power generations, respectively, at bus-i. $P_{i u}$ and $Q_{i u}$ are the injections, given by equations (1) - (4), at bus- $i$ due to the UPFC. $P_{D i}$ and $Q_{D i}$ are the base case real and reactive power demands, respectively, at the bus- $i$.

Equations (11) and (12), with UPFC, are function of bus voltage magnitudes $(\boldsymbol{V})$ and angles $(\boldsymbol{\delta})$, magnitude $\left(V_{s}\right)$ and angle $\left(\phi_{s}\right)$ of the injected voltage due to UPFC.

$$
\begin{aligned}
& P_{i s}=f_{p i}\left(\boldsymbol{V}, \boldsymbol{\delta}, \phi_{s}, V_{s}\right) \\
& Q_{i s}=f_{q i}\left(\boldsymbol{V}, \boldsymbol{\delta}, \phi_{s}, V_{s}\right)
\end{aligned}
$$

From Taylor's series expansion, equation (13) can be written as,

$$
\left[\begin{array}{c}
\Delta \boldsymbol{f}_{p} \\
\Delta \boldsymbol{f}_{q}
\end{array}\right]=[\boldsymbol{J}]\left[\begin{array}{c}
\Delta \boldsymbol{\delta} \\
\Delta \boldsymbol{V}
\end{array}\right]+\left[\boldsymbol{K}_{\phi_{s}}\right]\left[\Delta \phi_{s}\right]+\left[\boldsymbol{K}_{V_{s}}\right]\left[\Delta V_{s}\right]
$$

where, variables written in bold face are the vector quantities and

$$
\begin{aligned}
& {[\boldsymbol{J}]=\left[\begin{array}{ll}
\frac{\partial \boldsymbol{f}_{p}}{\partial \boldsymbol{\delta}} & \frac{\partial \boldsymbol{f}_{p}}{\partial \boldsymbol{V}} \\
\frac{\partial \boldsymbol{f}_{q}}{\partial \boldsymbol{\delta}} & \frac{\partial \boldsymbol{f}_{q}}{\partial \boldsymbol{V}}
\end{array}\right]=\left[\begin{array}{ll}
\frac{\partial \boldsymbol{P}}{\partial \boldsymbol{\delta}} & \frac{\partial \boldsymbol{P}}{\partial \boldsymbol{V}} \\
\frac{\partial \boldsymbol{Q}}{\partial \boldsymbol{\delta}} & \frac{\partial \boldsymbol{Q}}{\partial \boldsymbol{V}}
\end{array}\right] ;} \\
& {\left[\boldsymbol{K}_{\phi_{s}}\right]=\left[\begin{array}{c}
\frac{\partial \boldsymbol{f}_{p}}{\boldsymbol{V}_{s} \partial \phi_{s}} \\
\frac{\partial \mathrm{f}_{q}}{\boldsymbol{V}_{s} \partial \phi_{s}}
\end{array}\right]=\left[\begin{array}{c}
\frac{\partial \boldsymbol{P}}{\boldsymbol{V}_{s} \partial \phi_{s}} \\
\frac{\partial \boldsymbol{Q}}{\boldsymbol{V}_{s} \partial \phi_{s}}
\end{array}\right] ; \quad\left[\boldsymbol{K}_{\boldsymbol{V}_{s}}\right]=\left[\begin{array}{c}
\frac{\partial \boldsymbol{f}_{p}}{\partial \boldsymbol{V}_{s}} \\
\frac{\partial \boldsymbol{f}_{q}}{\partial \boldsymbol{V}_{s}}
\end{array}\right]=\left[\begin{array}{c}
\frac{\partial \boldsymbol{P}}{\partial \boldsymbol{V}_{s}} \\
\frac{\partial \boldsymbol{Q}}{\partial \boldsymbol{V}_{s}}
\end{array}\right]} \\
& {\left[\begin{array}{c}
\Delta \boldsymbol{\delta} \\
\Delta \boldsymbol{V}
\end{array}\right]=\left[\begin{array}{l}
{\left[\begin{array}{l}
\Delta \delta_{2} \Delta \delta_{3} \ldots \Delta \delta_{i} \ldots \Delta \delta_{\mathrm{N}_{\mathrm{b}}} \\
]^{T} \\
{\left[\Delta V_{2} \Delta V_{3} \ldots \Delta V_{i} \ldots \Delta V_{\mathrm{N}_{\mathrm{b}}}\right.}
\end{array}\right]^{T}}
\end{array}\right] ;}
\end{aligned}
$$

$\left[\Delta \boldsymbol{V}_{s}\right]=\left[\Delta V_{s, i j} \ldots \ldots \ldots \ldots\right]^{\mathrm{T}}$; and $\left[\Delta \boldsymbol{\phi}_{s}\right]=\left[\Delta \phi_{s, i j} \ldots \ldots \ldots \ldots\right]^{\mathrm{T}}$; $\forall i, j \in N_{b}$, represent injected voltage magnitude and phase angle vectors, respectively.
The derivatives corresponding to the slack bus is not included in the above derivation and shunt current $I_{q}$ has been taken as zero. The size of matrices $[\boldsymbol{J}]$ and $[\boldsymbol{K}]$ are $\left(2 N_{b}-2\right) \times\left(2 N_{b}-2\right)$ and $\left(2 N_{b}-2\right) \times\left(N_{l}\right)$, respectively.

In equation (14), the change in loading has been assumed to be met by the slack bus generator, which can be rewritten as,

$$
\begin{aligned}
& {\left[\begin{array}{c}
\Delta \boldsymbol{\delta} \\
\Delta \boldsymbol{V}
\end{array}\right]=-\left[\boldsymbol{N}_{\phi_{s}}\right]\left[\Delta \phi_{s}\right]-\left[\boldsymbol{N}_{V_{s}}\right]\left[\Delta \boldsymbol{V}_{s}\right]} \\
& \text { where, }\left[\boldsymbol{N}_{\phi_{s}}\right]=[\boldsymbol{J}]^{-1}\left[\boldsymbol{K}_{\phi_{s}}\right] ;\left[\boldsymbol{N}_{V_{s}}\right]=[\boldsymbol{J}]^{-1}\left[\boldsymbol{K}_{V_{s}}\right]
\end{aligned}
$$

The line real power flow $\left(\boldsymbol{P}_{\boldsymbol{m}}\right)$ can be represented in terms of voltage magnitudes, voltage angles and UPFC parameters as,

$$
\boldsymbol{P}_{m}=\boldsymbol{f}\left(\boldsymbol{V}, \boldsymbol{\delta}, \phi_{s}, \boldsymbol{V}_{s}\right)
$$

Using the Taylor's series expansion, equation (16) can be expressed as,

$\left[\Delta \boldsymbol{P}_{m}\right]=\left[\frac{\partial \boldsymbol{P}_{m}}{\partial \boldsymbol{\delta}} \frac{\partial \boldsymbol{P}_{m}}{\partial \boldsymbol{V}}\right]\left[\begin{array}{l}\Delta \boldsymbol{\delta} \\ \Delta \boldsymbol{V}\end{array}\right]+\left[\frac{\partial \boldsymbol{P}_{m}}{\boldsymbol{V}_{s} \partial \boldsymbol{\phi}_{s}}\right]\left[\Delta \phi_{s}\right]+\left[\frac{\partial \boldsymbol{P}_{m}}{\partial \boldsymbol{V}_{s}}\right]\left[\Delta \boldsymbol{V}_{s}\right]$

From equations (15) and (17), the following relationship can be obtained.

$$
\begin{gathered}
{\left[\Delta \boldsymbol{P}_{m}\right]=[\boldsymbol{M}]\left[-\left[\boldsymbol{N}^{\phi_{s}}\right]\left[\Delta \phi_{s}\right]-\left[\boldsymbol{N}^{V_{s}}\right]\left[\Delta \boldsymbol{V}_{s}\right]\right]+} \\
\quad\left[\boldsymbol{T}^{\phi_{s}}\right]\left[\Delta \phi_{s}\right]+\left[\boldsymbol{T}^{V_{s}}\right]\left[\Delta \boldsymbol{V}_{s}\right] \\
\quad \text { or } \quad\left[\boldsymbol{P}_{m}\right]=\left[\boldsymbol{M N} \boldsymbol{T}^{\phi_{s}}\right]\left[\Delta \phi_{s}\right]+\left[\boldsymbol{M} \boldsymbol{N} \boldsymbol{T}^{V_{s}}\right]\left[\Delta \boldsymbol{V}_{s}\right]
\end{gathered}
$$

where, $[\boldsymbol{M}]=\left[\frac{\partial \boldsymbol{P}_{m}}{\partial \boldsymbol{\delta}} \frac{\partial \boldsymbol{P}_{m}}{\partial \boldsymbol{V}}\right]$

$$
\begin{gathered}
{\left[\boldsymbol{T}^{\phi_{s}}\right]=\left[\frac{\partial \boldsymbol{P}_{m}}{\boldsymbol{V}_{s} \partial \phi_{s}}\right] ;\left[\boldsymbol{T}^{V_{s}}\right]=\left[\frac{\partial \boldsymbol{P}_{m}}{\partial \boldsymbol{V}_{s}}\right] ;} \\
{\left[\boldsymbol{M} \boldsymbol{N} \boldsymbol{T}^{\phi_{s}}\right]=\left[\left[\boldsymbol{T}^{\phi_{s}}\right]-[\boldsymbol{M}]\left[\boldsymbol{N}^{\phi_{s}}\right]\right] \text { and }} \\
{\left[\boldsymbol{M} \boldsymbol{N} \boldsymbol{T}^{V_{s}}\right]=\left[\left[\boldsymbol{T}^{V_{s}}\right]-[\boldsymbol{M}]\left[\boldsymbol{N}^{V_{s}}\right]\right]}
\end{gathered}
$$

From equation (19),

$$
\begin{aligned}
& {\left[\frac{\Delta \boldsymbol{P}_{m}^{\phi_{s}}}{\boldsymbol{V}_{s} \Delta \phi_{s}}\right]=\left[\boldsymbol{M N} \boldsymbol{T}^{\phi_{s}}\right]} \\
& {\left[\frac{\Delta \boldsymbol{P}_{m}^{V_{s}}}{\Delta \boldsymbol{V}_{s}}\right]=\left[\boldsymbol{M} \boldsymbol{N} \boldsymbol{T}^{V_{s}}\right]}
\end{aligned}
$$

For deriving the PI sensitivity terms using ac power flow approximation, the value of ' $a$ ' and ' $w_{m}$ ' in equation (5) have been taken as unity. Substituting equations (20) and (21) in equation (8), a new set of PI sensitivity factors are obtained and can be written as

$$
\begin{aligned}
& F_{1}^{k}=\frac{\partial P I}{\partial V_{s}}=\sum_{m=1}^{N_{l}} P_{m}\left(\frac{1}{P_{m}^{\max }}\right)^{2}\left[M N T_{m}^{V_{s}}\right] \\
& F_{2}^{k}=\frac{\partial P I}{V_{s} \partial \phi_{s}}=\sum_{m=1}^{N_{l}} P_{m}\left(\frac{1}{P_{m}^{\max }}\right)^{2}\left[M N T_{m}^{\phi_{s}}\right]
\end{aligned}
$$

The sensitivities of real power flow Performance Index (PI) with respect to UPFC's series parameters (voltage 
magnitude and phase injection) have been calculated by both dc and ac power flow approximation. The following criteria have been used for optimal placement of an UPFC, in the system.

- The branches having transformers are not considered for the UPFC placement.

- The line having highest absolute PI angle sensitivities $\left(C_{2}{ }^{k} \& F_{2}{ }^{k}\right)$ with respect to the change in injected voltage phase angle $\left(\phi_{s}\right)$ is considered as the best location for the UPFC placement followed by other lines having next highest sensitivities.

- When the values of absolute PI angle sensitivities $\left(C_{2}{ }^{k}\right.$ $\left.\& F_{2}{ }^{k}\right)$ are very close to each other, the line having the highest absolute value of the PI voltage sensitivities $\left(C_{l}{ }^{k} \& F_{l}{ }^{k}\right)$ with respect to the change in injected voltage magnitude $V_{s}$ is considered as the best location for the UPFC.

\section{Methodology to Assess the Impact of Optimal UPFC Placement}

The effectiveness of the proposed PI sensitivity factor based approach for UPFC placement has been verified in terms of reduction in the line flow Performance Index (PI) values. For this purpose, an Optimal Power Flow (OPF) formulation with line real flow $\left(P_{m}\right)$ as control variable, as described below, has been used.

$$
\text { Minimize } P I=\sum_{m=1}^{N_{l}} \frac{1}{2 a}\left(\frac{P_{m}}{P_{m}^{\max }}\right)^{2 a}
$$

subject to the following constraints:

(a) Equality constraints: Power balance equations corresponding to both real and reactive powers at each bus must be satisfied. This can be expressed, in general form, as

$$
G\left(V, \delta, Y, V_{s}, \phi_{s}\right)=0 \text {; }
$$

where, $\mathrm{G}$ is the vector of the real and the reactive power flow equations at all the buses.

(b) Inequality constraints: These include the operating limits on the various power system variables and the parameters of the UPFC, as given below.

$$
\begin{aligned}
& Q_{G}^{\text {min }} \leq \boldsymbol{Q}_{G} \leq \boldsymbol{Q}_{G}^{\text {max }} \\
& \boldsymbol{V}^{\text {min }} \leq \boldsymbol{V} \leq \boldsymbol{V}^{\text {max }} \\
& \boldsymbol{\delta}^{\text {min }} \leq \boldsymbol{\delta} \leq \boldsymbol{\delta}^{\text {max }} \\
& 0 \leq V_{s} \leq V_{s}^{\max }, \\
& -\pi \leq \phi_{s} \leq \pi
\end{aligned}
$$

Equation (26) represents the limits on the reactive power generations. The limits on the bus voltage magnitude and angle are given by equations (27) and (28), respectively. Equation (29) represents the limits on the UPFC parameters $\left(V_{s}, \phi_{s}\right)$. The values of exponent ' $a$ ' and $\mathrm{w}_{\mathrm{m}}$ have been taken as 2 and 1 , respectively.

The above OPF problem involves a nonlinear objective function and a set of nonlinear equality and inequality constraints. This problem can be solved by any nonlinear optimization procedure. In this work, optimization software called Generalized Algebraic Modeling of System (GAMS) [17] has been used to obtain the optimal solution.

\section{System Studies}

The proposed line flow PI sensitivity method, derived based on de power flow as well as ac power flow approximations, for optimal location of UPFC has been tested on IEEE 30bus [13] and NREB 246-bus Indian [16] systems. Fig. 3 shows $400 \mathrm{kV}$ and higher voltage network and the geographical locations of the NREB system covering nine states of India. The results of the system studies are given in following subsections.

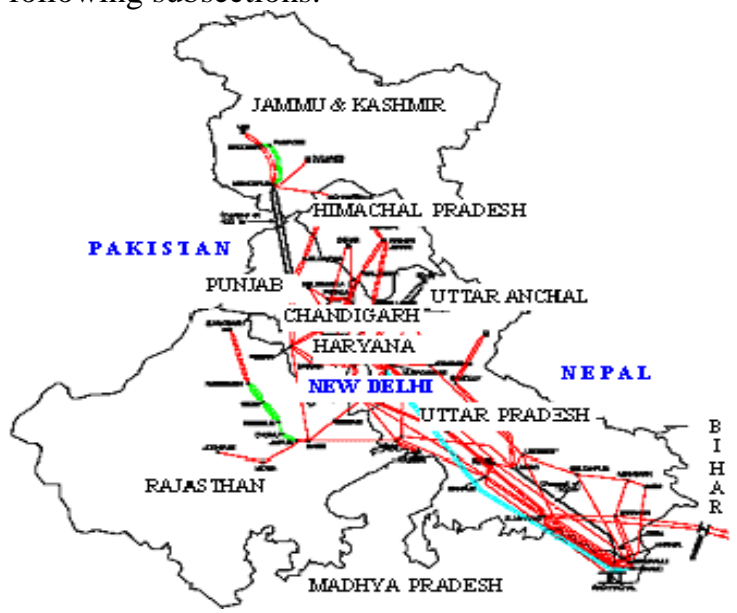

Figure 3. NREB 246-bus Indian system [16] (connections shown are $400 \mathrm{kV}$ and above only)

\subsection{Line outage Contingency Ranking}

To obtain the critical contingencies (line outages) in the IEEE 30-bus system and 246-bus NREB system, the PI values, as defined in equation (5), are computed for each of the single-line outage (N-1 contingency) cases. For both the systems, five most critical lines are listed in Table 1. Contingencies, for which feasible ac load flow solutions have not been obtained, are not included in this list. For the base case, the PI value obtained from the ac power flow solution for the IEEE 30-bus and NREB 246-bus systems are found to be 0.4142 and 5.4391, respectively.

Table 1

Line outage contingency ranking based on PI values in 30bus and 246-bus systems

\begin{tabular}{|c|c|c|c|c|c|c|}
\hline \multirow{2}{*}{$\begin{array}{c}\text { Rank } \\
\text { order }\end{array}$} & \multicolumn{2}{|c|}{ IEEE 30-bus system } & \multicolumn{3}{c|}{ NREB 246-bus system } \\
\cline { 2 - 7 } & $\begin{array}{c}\text { Line } \\
\text { outage }\end{array}$ & $\begin{array}{c}\text { End buses } \\
i-j\end{array}$ & PI & $\begin{array}{c}\text { Line } \\
\text { outage }\end{array}$ & $\begin{array}{c}\text { End buses } \\
i-j\end{array}$ & PI \\
\hline & $\begin{array}{c}\text { Intact } \\
\text { case }\end{array}$ & - & 0.4142 & Intact case & - & 5.4391 \\
\hline 1 & 12 & $1-27$ & 1.9030 & 223 & $154-240$ & 6.8691 \\
\hline 2 & 33 & $27-11$ & 1.8160 & 355 & $223-39$ & 6.5420 \\
\hline 3 & 5 & $2-5$ & 0.6475 & 206 & $137-141$ & 6.5326 \\
\hline 4 & 7 & $11-13$ & 0.6168 & 197 & $18-134$ & 6.4473 \\
\hline 5 & 9 & $13-12$ & 0.5889 & 359 & $233-235$ & 6.2829 \\
\hline
\end{tabular}




\subsection{Optimal Placement of UPFC in IEEE 30-bus System and its Impact on System Security}

PI sensitivity factors $C_{1}{ }^{k} \& C_{2}{ }^{k}$, based on dc power flow method and $F_{1}{ }^{k} \& F_{2}{ }^{k}$, based on ac power flow approximation, with respect to the UPFC parameters, are obtained and shown in Table 2. First column shows the priority number, columns 2 and 3 show the PI sensitivities with respect to the UPFC parameters based upon dc and ac power flow approximations, respectively.

Table 2

PI sensitivity factors (30-bus system)

\begin{tabular}{|c|c|c|c|c|c|c|c|c|}
\hline \multirow{2}{*}{$\begin{array}{c}\text { Rank } \\
\text { order }\end{array}$} & \multicolumn{6}{|c|}{ dc power flow approximation [7] } & \multicolumn{3}{|c|}{ ac power flow approximation } \\
\cline { 3 - 10 } & Line no. & $C_{I}{ }^{k}$ & $\begin{array}{c}\text { Line } \\
\text { no. }\end{array}$ & $C_{2}{ }^{k}$ & Line no. & $F_{I}{ }^{k}$ & $\begin{array}{c}\text { Line } \\
\text { no. }\end{array}$ & $F_{2}{ }^{k}$ \\
\hline 1 & 33 & -0.3134 & 12 & -2.0657 & 12 & -1.0626 & 12 & -2.0385 \\
\hline 2 & 12 & -0.2639 & 33 & -2.0295 & 33 & -0.7441 & 33 & -2.0279 \\
\hline 3 & 7 & -0.1722 & 11 & 1.7068 & 11 & 0.6687 & 11 & 2.0185 \\
\hline 4 & 11 & 0.1501 & 7 & -0.9631 & 14 & 0.3785 & 14 & 1.1567 \\
\hline 5 & 14 & 0.1372 & 14 & 0.8885 & 7 & -0.2380 & 7 & -0.6874 \\
\hline 6 & 6 & 0.0897 & 6 & 0.5018 & 9 & -0.1606 & 6 & 0.5659 \\
\hline 7 & 5 & 0.0743 & 9 & -0.3463 & 8 & 0.1208 & 9 & -0.3112 \\
\hline 8 & 9 & -0.0740 & 8 & 0.3325 & 6 & 0.1060 & 5 & 0.3061 \\
\hline 9 & 8 & 0.0711 & 5 & 0.3087 & 5 & 0.0941 & 8 & 0.3029 \\
\hline 10 & 3 & -0.0648 & 3 & -0.2420 & 38 & 0.0598 & 13 & 0.2087 \\
\hline
\end{tabular}

Table 3

Impact of UPFC placement based on $C_{l}{ }^{k}$ (30-bus system)

\begin{tabular}{|c|c|c|c|c|c|c|c|}
\hline \multirow{2}{*}{$\begin{array}{c}\text { Rank } \\
\text { order }\end{array}$} & $\begin{array}{c}\text { Line } \\
\text { no. }\end{array}$ & \multirow{2}{*}{$C_{l}{ }^{k}$} & \multicolumn{2}{|c|}{$\begin{array}{c}\text { Considering variation of } \\
V_{s}(\mathrm{pu}) \text { only }\end{array}$} & \multicolumn{3}{|c|}{$\begin{array}{c}\text { Considering variation of } \\
V_{s}(\mathrm{pu}) \text { and } \phi_{s}(\mathrm{rad})\end{array}$} \\
\cline { 5 - 9 } & & Optimal $P I$ & $V_{s}$ & $\begin{array}{c}\text { Optimal } \\
P I\end{array}$ & $V_{s}$ & $\phi_{s}$ \\
\hline 1 & 33 & -0.3134 & 0.3178 & 0.1873 & 0.2862 & 0.1079 & 1.1663 \\
\hline 2 & 12 & -0.2639 & 0.2949 & 0.2000 & 0.2858 & 0.1028 & 1.0293 \\
\hline 3 & 7 & -0.1722 & 0.3754 & 0.0682 & 0.3574 & 0.0708 & 1.7240 \\
\hline 4 & 11 & 0.1501 & 0.3304 & 0.1539 & 0.2869 & 0.1179 & 1.5967 \\
\hline 5 & 14 & 0.1372 & 0.3726 & 0.1219 & 0.3237 & 0.1531 & 1.6194 \\
\hline 6 & 6 & 0.0897 & 0.3820 & 0.0642 & 0.3581 & 0.1043 & 1.7329 \\
\hline
\end{tabular}

Table 3 shows the optimal PI values obtained after optimal placement of the UPFC in few lines having high value of the PI sensitivity factors $\left(C_{I}^{k}\right)$. Optimal values of the PIs, given in the $4^{\text {th }}$ column, are when only series injected voltage magnitude of the UPFC is varied and those given in the $5^{\text {th }}$ column are when both the magnitude and phase angle of the injected voltage by UPFC are varied in the corresponding lines. From Table 3, it can be seen that the line-12 is the best location for optimal placement of UPFC in the 30-bus system.

Table 4 shows the optimal PI values after placing the UPFC in the respective lines, one at a time, selected based on the PI sensitivity factors $C_{2}{ }^{k}$. The PI values given in the column 4 are obtained with the fixed values of series injected voltage magnitude (considered as $0.01 \mathrm{pu}$ ) and varying the phase angle injection by the UPFC. The optimal values of the series injected voltage angle are shown in the $4^{\text {th }}$ column. The effect of variation of both the series voltage magnitude and phase angle injection by the UPFC on optimal PI values is shown in the $5^{\text {th }}$ column. From Tables 2, 3 and 4, the best location for the UPFC placement, in the
IEEE 30-bus system, is found to be line-12, as the optimal PI value is minimum in most of the cases with the UPFC placement in this line.

Table 4

Impact of UPFC placement based on $C_{2}{ }^{k}$ (30-bus system)

\begin{tabular}{|c|c|c|c|c|c|c|c|}
\hline $\begin{array}{c}\text { Rank } \\
\text { order }\end{array}$ & \multirow{2}{*}{$\begin{array}{c}\text { Line } \\
\text { no. }\end{array}$} & \multirow{2}{*}{$C_{2}{ }^{k}$} & \multicolumn{2}{|c|}{$\begin{array}{c}\text { Considering variation of } \\
\phi_{s}(\mathrm{rad}) \text { only }\end{array}$} & \multicolumn{3}{|c|}{$\begin{array}{c}\text { Considering variation of } \\
V_{s}(\mathrm{pu}) \text { and } \phi_{s}(\mathrm{rad})\end{array}$} \\
\cline { 3 - 8 } & & optimal $P I$ & $\phi_{s}$ & $\begin{array}{c}\text { optimal } \\
P I\end{array}$ & $V_{s}$ & $\phi_{s}$ \\
\hline 1 & 12 & -2.0657 & 0.3668 & 1.1114 & 0.2858 & 0.1028 & 1.0293 \\
\hline 2 & 33 & -2.0295 & 0.3676 & 1.2382 & 0.2862 & 0.1079 & 1.1663 \\
\hline 3 & 11 & 1.7068 & 0.3686 & 1.2638 & 0.2869 & 0.1179 & 1.5967 \\
\hline 4 & 7 & -0.9631 & 0.3775 & 1.2407 & 0.3574 & 0.0708 & 1.7240 \\
\hline 5 & 14 & 0.8885 & 0.3775 & 1.3234 & 0.3237 & 0.1531 & 1.6194 \\
\hline 6 & 6 & 0.5018 & 0.3805 & 1.3654 & 0.3581 & 0.1043 & 1.7329 \\
\hline
\end{tabular}

It can be seen that the best locations for the UPFC placement based on the optimal PI values (Table 4, column 5) are lines-12, 33, 11, 14, 7 and 6 in the rank order. However, the ranking order obtained from the sensitivity factors $\left(C_{2}{ }^{k}\right)$ are lines-12, 33, 11, 7, 14, and 6, which are almost similar, but not the same.

The rank order of line provided by the PI sensitivity factors $\left(F_{1}{ }^{k}, F_{2}{ }^{k}\right)$ obtained using ac power flow approximation, as shown in Table 2 , for the optimal locations of UPFC are the lines-12, 33, 11, 14, 7, and 6, respectively. This order is exactly same as verified through the optimal value of the PI obtained after placement of the UPFC in these lines. This confirms the validity of the proposed PI sensitivity factors, based on ac power flow approximation, for the UPFC placement (Table 4). It can also be seen from Table 2 that the PI sensitivity factors with respect to the injected voltage phase angle provide more accurate result for optimal UPFC location in order to improve system security, as reflected by the optimal PI values.

\subsection{Optimal Placement of UPFC in NREB 246-bus System and study its Impact on System Security}

The PI sensitivities, based on the dc \& ac power flow method, have also been computed for the 246-bus system, as defined in equations (6)-(7) and (22)-(23), which are listed in Table 5 .

Table 5

PI sensitivity factors (246-bus system)

\begin{tabular}{|c|c|c|c|c|c|c|c|c|}
\hline \multirow[b]{2}{*}{$\begin{array}{l}\text { Rank } \\
\text { order }\end{array}$} & \multicolumn{4}{|c|}{ dc power flow approximation [7] } & \multicolumn{4}{|c|}{ ac power flow approximation } \\
\hline & $\begin{array}{c}\text { Line } \\
\text { no. }\end{array}$ & $C_{1}^{k}$ & $\begin{array}{c}\text { Line } \\
\text { no. }\end{array}$ & $C_{2}{ }^{k}$ & $\begin{array}{c}\text { Line } \\
\text { no. }\end{array}$ & $F_{l}^{k}$ & $\begin{array}{c}\text { Line } \\
\text { no. }\end{array}$ & $F_{2}{ }^{k}$ \\
\hline 1 & 213 & 2.7445 & 198 & -19.2473 & 198 & 22.3704 & 213 & -65.6967 \\
\hline 2 & 218 & -2.5946 & 218 & -19.1484 & 218 & 21.8200 & 218 & 65.4654 \\
\hline 3 & 198 & -2.4618 & 213 & 19.0 & 213 & -21.1 & 198 & 65.2 \\
\hline 4 & 193 & -2.1875 & 197 & -17.0890 & 197 & 14.5429 & 206 & -50.0659 \\
\hline 5 & 197 & -2.1563 & 193 & -16.9992 & 193 & 14.0577 & 205 & 49.8826 \\
\hline 6 & 205 & -1.9746 & 205 & -12.5719 & 206 & -13.9627 & 197 & 44.9844 \\
\hline 7 & 206 & 1.9741 & 206 & 12.5691 & 205 & 13.8662 & 193 & 44.7622 \\
\hline 8 & 196 & 1.9498 & 196 & 12.1520 & 174 & 10.9895 & 196 & -44.0145 \\
\hline 9 & 349 & -1.1543 & 191 & 6.4431 & 196 & -10.7936 & 191 & -35.6772 \\
\hline 10 & 191 & 1.0888 & 276 & -5.8666 & 191 & -10.3694 & 173 & -34.2384 \\
\hline
\end{tabular}


Table 6 shows the optimal PI values, obtained after optimal placement of the UPFC in few lines, having high value of the PI sensitivity factors $\left(C_{1}{ }^{k}\right)$. Optimal values of the PIs, given in the $4^{\text {th }}$ column, are when only series injected voltage of UPFC is varied and those given in the $5^{\text {th }}$ column are when both the magnitude and the phase angle of the injected voltage by the UPFC are varied in the corresponding lines. From Table 6, it can be seen that the line-213 is the best location for the optimal placement of the UPFC in the 246-bus system.

Table 6

Impact of UPFC placement based on $C_{l}{ }^{k}$ (246-bus system)

\begin{tabular}{|c|c|c|c|c|c|c|c|}
\hline \multirow{2}{*}{$\begin{array}{c}\text { Priority } \\
\text { no. }\end{array}$} & $\begin{array}{c}\text { Line } \\
\text { no. }\end{array}$ & $C_{I}{ }^{k}$ & \multicolumn{2}{|c|}{$\begin{array}{c}\text { Considering } \\
\text { variation of } \\
V_{s}(\mathrm{pu}) \text { only }\end{array}$} & \multicolumn{3}{|c|}{$\begin{array}{c}\text { Considering variation of } \\
V_{s}(\mathrm{pu}) \text { and } \phi_{s}(\mathrm{rad})\end{array}$} \\
\cline { 4 - 8 } & & Optimal PI & $V_{s}$ & Optimal PI & $V_{s}$ & $\phi_{s}$ \\
\hline 1 & 213 & 2.7445 & 4.9446 & 0.0543 & 4.9445 & 0.0492 & -3.1093 \\
\hline 2 & 218 & -2.5946 & 4.9446 & 0.0541 & 4.9446 & 0.0489 & -3.1121 \\
\hline 3 & 198 & -2.4618 & 4.9447 & 0.0532 & 4.9447 & 0.0487 & 0.0306 \\
\hline 4 & 193 & -2.1875 & 4.9804 & 0.0361 & 4.9760 & 0.0827 & 2.9697 \\
\hline 5 & 197 & -2.1563 & 4.9811 & 0.0360 & 4.9812 & 0.0358 & -3.1416 \\
\hline
\end{tabular}

Table 7 shows the optimal PI values after placing the UPFC in the respective lines, one at a time selected based on the PI sensitivity factors $C_{2}{ }^{k}$. The PI values, given in the column 4 , are obtained with the fixed values of the series injected voltage magnitude (considered as $0.01 \mathrm{pu}$ ) and varying the voltage phase angle injection by the UPFC. The optimal values of the series injected angle are shown in the $4^{\text {th }}$ column. The effect of both the series voltage magnitude and phase angle variation by the UPFC, on the optimal PI values, is shown in the $5^{\text {th }}$ column. From Tables 5, 6 and 7, the best location for the UPFC placement, in the 246-bus system, is found to be line-213, as the optimal PI value is minimum in most of the cases with the UPFC placement in this line.

Table 7

Impact of UPFC placement based on $C_{2}{ }^{k}$ (246-bus system)

\begin{tabular}{|c|c|c|c|c|c|c|c|}
\hline \multirow{2}{*}{$\begin{array}{c}\text { Priority } \\
\text { no. }\end{array}$} & $\begin{array}{c}\text { Line } \\
\text { no. }\end{array}$ & \multirow{2}{*}{$C_{2}{ }^{k}$} & \multicolumn{2}{|c|}{$\begin{array}{c}\text { Considering } \\
\text { variation of } \\
\phi_{s}(\mathrm{rad}) \text { only }\end{array}$} & \multicolumn{3}{|c|}{$\begin{array}{c}\text { Considering variation of } \\
V_{s}(\mathrm{pu}) \text { and } \phi_{s}(\mathrm{rad})\end{array}$} \\
\cline { 5 - 9 } & & & Optimal PI & $\phi_{s}$ & $\begin{array}{c}\text { Optimal } \\
\text { PI }\end{array}$ & $V_{s}$ & $\phi_{s}$ \\
\hline 1 & 198 & -19.2473 & 4.9605 & 1.2307 & 4.9447 & 0.0487 & 0.0306 \\
\hline 2 & 218 & -19.1484 & 4.9604 & 1.2370 & 4.9446 & 0.0489 & -3.1121 \\
\hline 3 & 213 & 19.0337 & 4.9604 & 1.2391 & 4.9445 & 0.0492 & -3.1093 \\
\hline 4 & 197 & -17.0890 & 4.9882 & 0.9491 & 4.9812 & 0.0358 & -3.1416 \\
\hline 5 & 193 & -16.9992 & 4.9879 & 0.9506 & 4.9860 & 0.0827 & 2.9697 \\
\hline 6 & 205 & -12.5719 & 4.9808 & 1.3104 & 4.9493 & 0.1024 & 3.1416 \\
\hline 7 & 206 & 12.5691 & 4.9852 & 3.1416 & 4.9482 & 0.1246 & 2.5092 \\
\hline
\end{tabular}

The PI sensitivity factors, obtained using ac power flow approximation, are also shown in Table 5, gives the rank order for the optimal locations of UPFC as lines- 213, 218, 198, 206, 205, 197, and 193. This order is exactly same as verified through the optimal value of the PI, obtained after placement of UPFC in these lines. This confirms the validity of the proposed PI sensitivity based factors for the UPFC placement (Table 5). It can also be seen, from Table 5, that the PI sensitivity factors with respect to the injected voltage phase angle provides more accurate results for optimal location of the UPFC in order to improve system security, as reflected by the optimal PI values.

\subsection{UPFC Placement based on PI Sensitivity Factors at increased Loading Condition}

This case was simulated by increasing the loads at all the buses by $5 \%$ from their base case values in the 30-bus system. Table 8 shows the optimal location of UPFC based on the PI sensitivity factors obtained from dc \& ac power flow approximations.

Table 8

PI sensitivity factors with 5\% load increase (30-bus system)

\begin{tabular}{|c|c|c|c|c|c|c|c|c|}
\hline $\begin{array}{c}\text { Rank } \\
\text { order }\end{array}$ & $\begin{array}{c}\text { Lc power flow approximation [7] } \\
\text { no. }\end{array}$ & $C_{l}{ }^{k}$ & $\begin{array}{c}\text { Line } \\
\text { no. }\end{array}$ & $C_{l}{ }^{k}$ & $\begin{array}{c}\text { Line } \\
\text { no. }\end{array}$ & $F_{l}{ }^{k}$ & $\begin{array}{c}\text { Line } \\
\text { no. }\end{array}$ & $F_{2}{ }^{k}$ \\
\hline 1 & 33 & -0.4031 & 12 & -2.4924 & 12 & -2.2990 & 12 & -4.5272 \\
\hline 2 & 12 & -0.3394 & 33 & -2.4469 & 11 & 1.7007 & 33 & -4.4940 \\
\hline 3 & 7 & -0.2214 & 11 & 2.0637 & 33 & -1.5853 & 11 & 4.4272 \\
\hline 4 & 11 & 0.1938 & 7 & -1.1592 & 14 & 0.7925 & 14 & 2.1625 \\
\hline 5 & 14 & 0.1770 & 14 & 1.0743 & 7 & -0.6667 & 7 & -2.1222 \\
\hline 6 & 6 & 0.1161 & 6 & 0.6082 & 6 & 0.4693 & 6 & 1.5512 \\
\hline 7 & 5 & 0.0945 & 9 & -0.4131 & 9 & -0.3381 & 9 & -0.7416 \\
\hline 8 & 9 & -0.0942 & 8 & 0.3965 & 5 & 0.2875 & 5 & 0.7268 \\
\hline 9 & 8 & 0.0904 & 5 & 0.3681 & 8 & 0.2624 & 8 & 0.7263 \\
\hline 10 & 3 & -0.0827 & 3 & -0.2895 & 3 & -0.1063 & 3 & -0.1832 \\
\hline
\end{tabular}

The impact of the optimal placement of UPFC on PI value is given in Table 9, with the 5\% increase in loading. The PI value was found to be 0.5012 , when there was no UPFC in the system. From Table 8, it is found that the line12 is the most sensitive line for the placement of UPFC in the case of the increased loading case as well. The PI value improves from 0.5012, without UPFC, to 0.3669 , with UPFC placed in line-12.

Table 10 shows the sensitivity factors with increased loading in the 246-bus system using dc power flow approximation. It is found that the rank order of lines for optimal location of UPFC is the same as obtained through optimal PI values after placement of UPFC in these lines as shown in Table 9 for both series voltage and phase angle variations.

Table 9

PI sensitivity factors $\left(C_{1}{ }^{k} \& C_{2}{ }^{k}\right)$ and optimal PI values after UPFC placement in 30-bus system with 5\% load increase

\begin{tabular}{|c|c|c|c|c|c|c|c|c|}
\hline \multirow{2}{*}{$\begin{array}{l}\text { Rank } \\
\text { order }\end{array}$} & \multicolumn{4}{|c|}{$P I$ sensitivities } & \multicolumn{4}{c|}{ Optimal $P I$ values and UPFC } \\
& Line & $C_{l}{ }^{k}$ & Line & $C_{2}{ }^{k}$ & Line & $P I$ & $V_{s}(\mathrm{pu})$ & $\phi_{s}(\mathrm{rad})$ \\
\hline 1 & 33 & -0.4031 & 12 & -2.4924 & 12 & 0.3669 & 0.1117 & 0.9532 \\
\hline 2 & 12 & -0.3394 & 33 & -2.4469 & 33 & 0.3676 & 0.1177 & 1.1004 \\
\hline 3 & 7 & -0.2214 & 11 & 2.0637 & 11 & 0.3686 & 0.1301 & 1.6385 \\
\hline 4 & 11 & 0.1938 & 7 & -1.1592 & 7 & 0.4633 & 0.0758 & 1.6804 \\
\hline 5 & 14 & 0.1770 & 14 & 1.0743 & 14 & 0.4187 & 0.1654 & 1.6153 \\
\hline
\end{tabular}

Similarly, Tables 10 and 11 show the optimal location of UPFC, based on dc and ac power flow approximations, respectively, and its impact after placing them in 
corresponding lines, one at a time, for $0.5 \%$ load increase condition in 246-bus system. The base case condition of this system is already simulated at a peak load condition. Hence, only $0.5 \%$ load increase has been considered. The optimal PI value was obtained as 5.2181, when there was no UPFC in the system. From Table $10 \& 11$, it is found that the line213 is the most sensitive for the optimal placement of UPFC in the increased loading case as well. The PI value has improved from 5.2181, without UPFC, to 5.0961, with UPFC placed in line-213.

Table 10

PI sensitivity factors $\left(C_{1}{ }^{k} \& C_{2}{ }^{k}\right)$ and optimal PI values after UPFC placement in 246-bus system with $0.5 \%$ load increase (dc power flow approximation)

\begin{tabular}{|c|c|c|c|c|c|c|c|c|}
\hline \multirow{2}{*}{$\begin{array}{c}\text { Pr. } \\
\text { no. }\end{array}$} & \multicolumn{3}{|c|}{$P I$ sensitivities $C_{I}{ }^{k} \& C_{2}{ }^{k}$} & \multicolumn{4}{c|}{$P I$ values and optimal UPFC } \\
\cline { 2 - 9 } & Line & $C_{I}{ }^{k}$ & Line & $C_{2}{ }^{k}$ & Line & $P I$ & $V_{s}(\mathrm{pu})$ & $\phi_{s}(\mathrm{rad})$ \\
\hline 1 & 213 & -2.3692 & 213 & -14.2958 & 213 & 5.0961 & 0.0359 & 0.1945 \\
\hline 2 & 218 & 2.3691 & 218 & 14.2951 & 218 & 5.0962 & 0.0355 & -2.9486 \\
\hline 3 & 198 & 2.2820 & 198 & 14.3606 & 198 & 5.0964 & 0.0351 & -2.9485 \\
\hline 4 & 205 & 2.0284 & 193 & 11.3489 & 197 & 5.1111 & 0.0353 & -3.1416 \\
\hline 5 & 206 & -1.8659 & 197 & 11.3341 & 193 & 5.1188 & 0.0397 & -3.1416 \\
\hline 6 & 197 & 1.7112 & 206 & -11.0970 & 205 & 5.0968 & 0.1115 & 2.4432 \\
\hline 7 & 193 & 1.6929 & 205 & 11.0456 & 206 & 5.0966 & 0.1120 & 2.4419 \\
\hline
\end{tabular}

Table 11

PI sensitivity factors $\left(F_{1}{ }^{k} \& F_{2}{ }^{k}\right)$ in 246-bus system with $0.5 \%$ load increase (ac power flow approximation)

\begin{tabular}{|c|c|c|c|c|c|c|}
\hline $\begin{array}{c}\text { Rank } \\
\text { order }\end{array}$ & $\begin{array}{c}\text { Line } \\
\text { no. }\end{array}$ & $\begin{array}{c}\text { Buses } \\
(i-j)\end{array}$ & $F_{1}{ }^{k}$ & Line no. & $\begin{array}{c}\text { Buses } \\
(i-j)\end{array}$ & $F_{2}{ }^{k}$ \\
\hline 1 & 198 & $134-146$ & 26.4559 & 213 & $141-148$ & -72.8023 \\
\hline 2 & 218 & $146-148$ & 25.8230 & 218 & $146-148$ & 72.5350 \\
\hline 3 & 213 & $141-148$ & -25.0930 & 198 & $134-146$ & 72.3215 \\
\hline 4 & 197 & $18-134$ & 18.7002 & 197 & $18-134$ & 54.2561 \\
\hline 5 & 193 & $133-18$ & 18.1167 & 193 & $133-18$ & 53.9974 \\
\hline 6 & 206 & $137-141$ & -16.0120 & 206 & $137-141$ & -51.9355 \\
\hline 7 & 205 & $137-140$ & 15.8854 & 205 & $137-140$ & 51.7082 \\
\hline 8 & 196 & $133-183$ & -15.0548 & 196 & $133-183$ & -50.7227 \\
\hline 9 & 280 & $183-34$ & -12.1881 & 191 & $132-140$ & -36.7600 \\
\hline 10 & 174 & $17-34$ & 12.0331 & 173 & $17-229$ & -34.4049 \\
\hline
\end{tabular}

\subsection{Impact of Contingencies on Optimal UPFC Location and System Security}

To show the effectiveness of the proposed method under contingencies, the sensitivity factors and optimal PI values were also computed for different line outage cases (Table 1), which are shown in Tables 12 and 13 for the 30-bus and 246-bus systems, respectively. First column shows the line considered for outage and the second column shows the PI values at outage of the corresponding lines without placement of UPFC. In Tables 12 and 13, the column three presents the sensitivity factors $\left(C_{2}{ }^{k} \& F_{2}{ }^{k}\right)$ along with corresponding optimal PI values for the few lines in priority order after outage of critical lines, as listed in the first column. Only the sensitivity factors $\mathrm{C}_{2}{ }^{\mathrm{k}}$ and $\mathrm{F}_{2}{ }^{\mathrm{k}}$ with respect to the change in series injected voltage phase angle by the UPFC have been considered, as it provided better results in the base case. Due to the outage of lines, the most optimal locations of the UPFC changed.
Table 12

Optimal PI values under critical line outages in 30-bus system (dc \& ac power flow approximations)

\begin{tabular}{|c|c|c|c|c|c|c|c|}
\hline \multirow{2}{*}{$\begin{array}{l}\text { Line } \\
\text { outage }\end{array}$} & \multirow{2}{*}{$\begin{array}{l}P I \text { value after } \\
\text { line outage }\end{array}$} & \multicolumn{6}{|c|}{$\begin{array}{c}\text { Sensitivities } C_{2}{ }^{k} \& F_{2}{ }^{k} \text { and optimal } P I \text { values with } \\
\text { UPFC settings }\end{array}$} \\
\hline & & $\begin{array}{c}\text { Line } \\
\text { no. }\end{array}$ & $C_{2}{ }^{k}$ & $F_{2}{ }^{k}$ & Optimal $P I$ & $V_{s}(\mathrm{pu})$ & $\phi_{s}(\mathrm{rad})$ \\
\hline \multirow{5}{*}{$\begin{array}{c}12 \\
(1-17)\end{array}$} & \multirow{5}{*}{1.7530} & 12 & - & & - & - & - \\
\hline & & 33 & 0.013 & 0.043 & 1.7523 & 0.0040 & 0.0000 \\
\hline & & 11 & -1.714 & 0.469 & 1.7020 & 0.0908 & 0.2554 \\
\hline & & 14 & -0.560 & 0.170 & 1.7445 & 0.0479 & -0.3551 \\
\hline & & 7 & -0.364 & 0.061 & 1.7517 & 0.0130 & -0.1290 \\
\hline \multirow{5}{*}{$\begin{array}{c}33 \\
(27-11\end{array}$} & \multirow{5}{*}{1.6741} & 12 & -0.000 & 0.036 & 1.6741 & 0.0002 & 1.5140 \\
\hline & & 33 & - & - & - & - & - \\
\hline & & 11 & -1.631 & 0.510 & 1.6281 & 0.0885 & 0.2334 \\
\hline & & 14 & -0.535 & 0.157 & 1.6671 & 0.0421 & -0.3499 \\
\hline & & 7 & -0.369 & 0.053 & 1.6734 & 0.0131 & -0.1061 \\
\hline \multirow{5}{*}{$\begin{array}{c}5 \\
(2-5)\end{array}$} & \multirow{5}{*}{0.6183} & 12 & -1.039 & -2.153 & 0.5680 & 0.1073 & 0.0703 \\
\hline & & 33 & -1.011 & -2.232 & 0.6182 & 0.0092 & 0.4499 \\
\hline & & 11 & 0.703 & 2.153 & 0.5686 & 0.1121 & 2.1766 \\
\hline & & 14 & 0.677 & 1.357 & 0.5839 & 0.1330 & 2.2459 \\
\hline & & 7 & 0.011 & -0.500 & 0.6122 & 0.0702 & -0.3877 \\
\hline
\end{tabular}

From Table 12, the line-11 is found to be the most suitable location for the optimal placement of the UPFC in view of security enhancement during outage of the lines-12, 33 and 5 in the IEEE 30-bus system. From Table 13, the line-213 is found to be the most suitable location for the optimal placement of the UPFC in view of security enhancement during outage of the lines-223, 355 and 206 in the 246-bus system.

Table 13

Optimal PI values under critical line outage cases in 246-bus system (dc and ac power flow approximations)

\begin{tabular}{|c|c|c|c|c|c|c|c|}
\hline \multirow{2}{*}{$\begin{array}{l}\text { Line } \\
\text { outage }\end{array}$} & \multirow{2}{*}{$\begin{array}{c}P I \text { value } \\
\text { after } \\
\text { line } \\
\text { outage }\end{array}$} & \multicolumn{6}{|c|}{$\begin{array}{c}\text { Sensitivities } C_{2}{ }^{k} \& F_{2}{ }^{k} \text { and optimal } P I \text { values with } \\
\text { UPFC settings }\end{array}$} \\
\hline & & $\begin{array}{c}\text { Line } \\
\text { no. }\end{array}$ & $C_{2}{ }^{k}$ & $F_{2}^{k}$ & $\begin{array}{l}\text { Optimal } \\
P I\end{array}$ & $V_{s}(\mathrm{pu})$ & $\phi_{s}(\mathrm{rad})$ \\
\hline \multirow{7}{*}{$\begin{array}{c}223 \\
(154-240)\end{array}$} & \multirow{7}{*}{6.4608} & 213 & -19.711 & -73.556 & 6.3427 & 0.0525 & -3.1416 \\
\hline & & 218 & 19.7129 & 73.297 & 6.3433 & 0.0515 & -3.1416 \\
\hline & & 198 & 19.8103 & 73.0938 & 6.3441 & 0.0503 & -3.1416 \\
\hline & & 197 & 16.2741 & 50.6191 & 6.3770 & 0.0361 & -3.1416 \\
\hline & & 193 & -16.212 & 50.2972 & 6.3535 & 0.0504 & -0.4330 \\
\hline & & 206 & -11.935 & -48.997 & 6.2743 & 0.0387 & 0.7937 \\
\hline & & 205 & 11.8712 & 48.6857 & 6.2898 & 0.1001 & 3.1416 \\
\hline \multirow{7}{*}{$\begin{array}{c}355 \\
(223-39)\end{array}$} & \multirow{7}{*}{5.9063} & 213 & -19.059 & -65.655 & 5.7958 & 0.0485 & -3.1258 \\
\hline & & 218 & 19.0601 & 65.4231 & 5.7978 & 0.0205 & -2.6180 \\
\hline & & 198 & 19.1457 & 65.2377 & 5.7972 & 0.0153 & -2.0944 \\
\hline & & 197 & 17.1118 & 44.9845 & 5.8437 & 0.0096 & -2.0944 \\
\hline & & 193 & 17.1335 & 44.7686 & 5.8337 & 0.0745 & 2.9715 \\
\hline & & 206 & -12.640 & -50.022 & 5.6871 & 0.1239 & 2.5093 \\
\hline & & 205 & 12.5806 & 49.8449 & 5.7535 & 0.1020 & 3.1416 \\
\hline \multirow{7}{*}{$\begin{array}{c}206 \\
(137-141)\end{array}$} & \multirow{7}{*}{5.9772} & 213 & -38.083 & -68.580 & 5.5089 & 0.1145 & -3.1416 \\
\hline & & 218 & 38.0905 & 68.3635 & 5.5096 & 0.1137 & -3.1416 \\
\hline & & 198 & 38.2587 & 68.1860 & 5.4566 & 0.1900 & 2.9826 \\
\hline & & 197 & 39.2914 & 48.5513 & 5.6390 & 0.0743 & -3.1416 \\
\hline & & 193 & 39.3395 & 48.2905 & 5.6365 & 0.0757 & -3.1416 \\
\hline & & 206 & - & - & - & - & - \\
\hline & & 205 & 76.7267 & 88.1096 & 4.9868 & 0.1596 & 3.1416 \\
\hline
\end{tabular}

From all obtained results, it has been observed that the proposed PI sensitivity factors based approach that utilized 
ac power flow, provided more accurate location of the UPFC as compared to that obtained from the dc power flow based PI sensitivity factors method. The placement of the UPFC in a line, obtained from the proposed factors, has resulted in maximum reduction in the line real power flow performance index (PI) values. The optimal placements do not change for increase in system loading. However, the locations differ under critical contingency conditions. Moreover, sensitivities calculated using dc power flow method provides relatively less accurate location of the UPFC in the NREB 246-bus system.

\section{Conclusions}

Line loading security Performance Index (PI) sensitivity factors have been suggested in this work for optimal placement of UPFC for enhancing the security of the power system. The PI sensitivity factors have been obtained with respect to change in two of the UPFC parameters viz., magnitude and phase angle of the injected voltage in the lines. An Optimal Power Flow (OPF) formulation has been suggested to determine the optimal PI values, another way called as security measure, after placement of UPFC based on the proposed sensitivity factors, in order to validate accuracy of the method. Both ac and dc power flow approximations have been used to define the sensitivity factors and their results have been compared on IEEE 30bus and NREB 246-bus systems. The impact of the UPFC placement on the security enhancement of the power system has been established, in terms of optimal PI values along with the optimal control settings of the UPFC, for system intact and few critical contingency cases.

\section{References}

[1] Hingorani NG. Flexible AC transmission. IEEE Spectrum 1993; pp. 40-45.

[2] Gyugyi L. A unified power flow control concept for flexible AC transmission systems. IEE Proc. Part-C 1992; Vol. 139, No. 4, pp. 323-331.

[3] Singh SN, Srivastava SC. Corrective action planning to achieve a feasible optimum power flow solution. IEE Proc. Part-C 1995, Vol. 142, No. 6, pp. 576 -582.

[4] Galiana GD et al. Assessment and control of the impact of FACTS devices on power system performance. IEEE Trans. on Power Systems 1996, Vol. 11, No. 4, pp.1931-1936.

[5] Singh SN. Location of FACTS devices for enhancing power systems' security. The 2001 Large Engineering Systems Conference on Electric Power Engineering
(LESCOPE), Halifax, Nova Scotia, Canada 2001, pp. 162-166.

[6] Momoh JA, Zhu JZ, Boswell G, Hoffman S. Power system security enhancement by OPF with phase shifter. IEEE Trans. on Power systems 2001, Vol. 16, No. 2, pp. 287-293.

[7] Verma KS, Singh SN, Gupta HO. Location of UPFC for enhancing power systems' security in deregulated environment. Intl. Conference on Energy Automation and Information Technology IIT Kharagpur 2001, pp. 149-154.

[8] Singh SN, David AK. Congestion management by optimizing FACTS device allocation. Proc. of International conference on Electric utility deregulation \& restructuring and power technologies 2000, pp. 23-28.

[9] Yorino N, Araby EE, Sasaki H, harada S. A new formulation for FACTS allocation for security enhancement against voltage collapse. IEEE Trans on Power Systems 2003, Vol. 18, No. 1, pp. 3-10.

[10]Radu D, Besanger Y. A multi-objective genetic algorithm approach to optimal allocation of multi-type FACTS devices for power systems security. IEEE General Meeting 2006.

[11] Gerbex S, Cherkaoui R, Germond AJ. Optimal location of FACTS devices to enhance power system security. IEEE Power tech Conference 2003, Vol. 3, No. 7.

[12] Verma KS, Singh SN, Gupta HO. Optimal location of UPFC for congestion management. Electric Power Systems Research 2001, Vol. 58, No. 2, pp. 89-96.

[13] Freris LL. Sasson AM. Investigation of the load flow problem. Proc IEE 196, 115, pp. 1459-1469.

[14]Ejebe GC, Wollenberg BF. Automatic contingency selection. IEEE Trans. on Power Apparatus and Systems 1979; Vol. 98, No. 1, pp. 92-104.

[15] Wood AJ, Wollenberg BF, Power Generation, Operation and Control; John Wiley: New York; 1996.

[16] Northern Regional Load Dispatch Center Website: http://nrldc.org/.

[17] GAMS Release 2.50. A user's guide, GAMD Development Corporation; 1999.

[18] Alsac O, Sttot B. Optimal power flow with steady-state security. IEEE Trans. on Power Apparatus and Systems 1974; PAS-93, pp. 745-751.

[19] Stott B, Hobson E. Power system security control calculations using linear programming-Part I. IEEE Trans. on Power Apparatus and Systems 1978; PAS-97, pp.1713-1719. 